LUBLIN STUDIES IN MODERN LANGUAGES AND

LITERATURE 41(1), 2017, HTTP://WWW.LSMLL.UMCS.LUBLIN.PL, HTTP://LSMLL.JOURNALS.UMCS.PL

\author{
Nassier A. G. Al-Zubaidi \\ Baghdad University \\ Baghdad, Iraq
}

\title{
Wedding Invitation Genre: \\ Communicating Sociocultural Identities of Iraqi Society
}

\begin{abstract}
The present study examined the genre of Iraqi wedding invitation cards (WICs) in terms of its textual and visual components, and the impact of the social norms and assumptions on the articulation of these components. Drawing upon three analytic tools, namely, genre analysis proposed by Swales (1990) and Bhatia (2004), semiotic analysis suggested by Kress and Van Leeuwen (2001), and critical discourse analysis advocated by Fairclough (2010), a sample of 250 WICs was selected to be considered for analysis. Corpus analysis showed that Iraqi WICs varied in terms of their non-linguistic features like printed forms, colors, layouts, calligraphy, graphics, and paper materials. On the other hand, the underlying schematic organization of Iraqi WICs was built around seven component moves. Furthermore, Islamic religious beliefs and Iraqi socio-cultural system were clearly encoded in these wedding invitation texts affecting their organization structure.

Keywords: wedding invitation cards; genre analysis; semiotic analysis; socio-cultural practices
\end{abstract}


1. Introduction

Invitation is "a commemorative social action having the function of informing and requesting the presence or participation of a person(s) kindly and courteously to some place, gathering, entertainment, etc., or to do something" (Al-Ali 2006: 961). A wedding invitation is of relative significance for wedding as it is the starting step for the wedding ceremony that guests will notice before the commencement of wedding. The genre of wedding invitation cards belongs to a text typology commonly known as 'homely discourses' along with other ceremonial texts like birth announcements, thank-you notes and death notices (Miller 1984). Such kind of printed invitation cards shares common generic patterns and properties, and communicates many socio-cultural conventions and practices of the speech community wherein these texts are written.

Wedding is one of the most memorable and happiest moments in human life. It is "a day when two individuals embark on a life-long journey of togetherness" (Hill 2015: 15). A wedding invitation text is the first public manifestation of a young couple's co-constructed matrimonial discourse and marks the beginning of their marriage, as one of their 'rites of passage' (Leeds-Hurwitz 2002). It is typically a formal written letter requesting the attendance and participation of guests in a wedding ceremony, and generally sent to relatives, friends, and neighbors before the marriage ceremony. It typically contains information about the names of the host and the newly-wed couples, and the arrangements of the wedding ceremony.

As ceremonial texts existing in almost every society, wedding invitation cards (WICs) are a ubiquitous genre that many people around the world are well acquainted with. In Arabic, this kind of homely genre has received little investigative attention compared to research on a variety of academic and professional genres such as book reviews, research abstracts, introductions, etc. A motivating reason for considering WICs is its "highly conventionalized content and clearly demarked structure" (Clynes and Henry 2004: 226). The present research is intended to analyze a corpus of Iraqi wedding invitation cards to identify their textual and visual component patterns. 
In addition, it attempts to determine the influence of social, cultural, and religious aspects on the textual and visual organization of the genre of Iraqi WICs. To the best of the researcher's knowledge, no previous published research seems to examine the genre of Iraqi WICs. Hence, the present research is the first of its type that dedicates itself to close a lacuna in applied linguistics research.

2. Wedding invitation genre: related literature

The written genre of WICs belongs to a colony of homely discourses that are such socially constructed texts of everyday life including, among many, thank-you notes, congratulations, obituaries (Johns, 1997). WICs can be best described as an exemplary amalgam of language-culture chemistry. These cards serve the communicative function of informing people that a wedding ceremony will be held in a particular place and time, and guests' attendance to the ceremony will be pleasantly requested. There is a paucity of research on the homely genre of WICs, and the available studies are not many. In this respect, Mirzaei and Eslami (2013) confirm that despite the prevalence and importance of wedding invitation discourse, it has surprisingly received little attention. This means that there is a dearth of related studies that form the background of this study.

One of the earliest influential studies is Al-Ali's (2006), who examined a corpus of 200 Jordanian WICs collected by 45 undergraduates at Jordan University with an aim of identifying their discourse generic component patterns and the role played by the socio-cultural norms and values in shaping these texts. A detailed genre analysis specified eight obligatory and non-obligatory generic moves that generally appeared in Jordanian WICs. The result of critical discourse analysis, on the other hand, reveals that religious affiliation and masculine kinship authority play an important role in constructing the text component moves and coloring the lexical choices and naming practices.

Mirzaei and Eslami (2013) investigated the genre of Iranian WICs. It probed into the discourse and social variability evident in wedding invitation texts collected from 150 couples. The findings showed that, 
besides religion, other socioculturally emerging factors such as education, feminism, socioeconomic status, profession, and age had massively impacted the young couples' preference for a certain type of still prefabricated though modern discourse. More important, modern couples had created various discursive practices to serve their own interests largely inspired by the newly emerging societal influences or agendas. The findings of this study shed light on the sociocultural aspects that influenced the communicative behavior of Iranian youth and provided insights into innovative wedding invitation texts in Iran as shaped by sociocultural beliefs and values.

Faramarzi et al. (2015) analyzed the genre of WICs in Iran to find out the generic components, linguistic features used as well as the communicative functions expressed by the generic components. A corpus of 200 Iranian WICS was randomly selected. The results showed that the Iranian invitation genre was built around eight moves out of which one was optional. On the other hand, the wedding invitation card pockets were constructed of five moves out of which three were optional. Besides, the lexico-grammatical features and schematic structure reflected the influence of Iranian socio-cultural values.

To conclude, this study is different from the research reviewed above in that it examines a discourse community not examined before (Iraqi context) from multidisciplinary perspectives. This study makes a significant contribution as it investigates textual and visual aspects of the discourse of Iraqi wedding invitations. Here, it is necessarily believed that not only verbal features but visual ones as well can contribute a lot to achieving the communicative goals of the genre of WICs. Moreover, this study integrates a critical discourse analytical framework investigating how the textual and verbal components of WICs are interwoven with the socio-cultural practices.

In other words, the present study draws on a multimodal analysis that takes a combination of textual and visual modes of meaningmaking into account. Specifically, it probes into the analysis of the typical verbal and non-verbal features of the wedding invitation discourse, and the sociocultural norms embedded in this type of 
discourse. The results of this study can be promising for raising sociocultural awareness of how the genre of Iraqi WICs is articulated to serve its communicative purpose.

\section{Methods and procedures}

\subsection{Corpus collection procedures}

400 written WICs were randomly collected. The entire total was checked and examined to find out if there was any difference in the schematic structure of the genre of Iraqi WICs. In conclusion, there was relative similarity with regard to the overall generic organization of these written texts. Moreover, the WICs chosen were relatively similar in terms of text size. A sample of only 250 WICs was selected to be considered for analysis. The selected sample came from different sources. Some were accumulated from within the known circle of the researcher's undergraduate students of English major at Baghdad University, colleagues, relatives and friends; others were collected from some local printing houses in Baghdad.

As for the corpus collected from the researcher's known circle, the researcher ensured variability in terms of region, socioeconomic status, occupation, education level, and so forth to obtain a representative and clear picture of the genre of WICs in Iraqi society; though this was not applicable to the rest of study corpus. The WICs are printed in Modern Standard Arabic, the native tongue of the Arabic-speaking region in Iraq, covering the time period of 19952015. It is noteworthy that all WICs considered for analysis were exclusively for Muslim newly-wed couples reflecting the demographic distribution of Muslims compared to other minorities in Iraq. For ethical reasons, names and any other information that might reveal the identity of hosts and guests were removed.

\subsection{Corpus analysis procedures}

As far as the analysis of the present corpus is concerned, a multidisciplinary analytic framework was adopted. Three analytic tools were used for analyzing the corpus of Iraqi wedding invitations. 
For the analysis of underlying schematic structure of WICs including communicative goals, rhetorical component moves, and lexicogrammatical features, Swales' (1990) and Bhatia's (2004) theoretical frameworks were employed. Following Al-Ali's (2006) procedures, the move analysis starts with

scanning the texts to identify text units expressing particular functions. Assigning a function to each text unit is guided by the proposition that each individual unit communicates a particular rhetorical function which is different from that of the following contiguous text unit. Each of these text component portions has a particular function in relation to the overall communicative purpose of the wedding invitation genre (p. 698).

Iraqi WICs, thus, were analyzed in terms of their recurring component moves to determine how the Iraqi wedding hosts accomplish the communicative purpose of this genre as a socio-cultural activity or practice. Due to the difficulty of establishing the reliability of component move analysis, and to validate the corpus analysis, the researcher's analysis was double-checked by a university professor working as an inter-coder. The inter-coding reliability confirms that there was an 86 percent agreement on the present corpus analysis since the move boundaries of this genre were clearly delineated.

As to the analysis of non-linguistic features associated with WICs, Kress and Van Leeuwen's (2001) social semiotic multi-model of textual analysis was used. Dynamics like printed forms, colors, layouts, calligraphy, graphics, and paper materials were analyzed by means of this analytic paradigm. Then, Fairclough's (2010) model of CDA was followed to investigate how social, cultural and religious representations were encoded in the discourse of wedding invitations. Where possible both qualitative and quantitative methods were used to analyze the selected corpus. To cross-check the credibility of corpus analysis, some Iraqi people were surveyed and interviewed to give their opinions of the generic, semiotic and socio-cultural features identified in the present corpus. 


\section{Results and discussion}

4.1. Non-linguistic features of wedding invitations

It has been observed that there are certain non-verbal features that are pertinent to the genre of WICs serving its unique communicative function. In general, Iraqi WICs vary in terms of their printed forms, colors, layouts, calligraphy, graphics, and paper materials. All these visual features are optional in the present corpus.

Iraqi WICs are customarily printed in rectangular and square shapes. They are printed in an array of bright and shiny colors such as pink, red, purple, white, golden, beige, silver, and cream ranging from ready-designed cards to custom-designed ones. The use of such colors and designs helps achieve the communicative function of this genre. By and large, it has been noted that Iraqi higher class families tend to design their own cards rather than to choose ready-made ones as these cards cost more money and are relatively expensive. Also, the selection of certain colors and designs seem to display the socioeconomic status and education of the wed-couples in that Iraqi higher class families show a general tendency toward the use of elegant but simple designs and cold colors like beige, white and cream, whereas other families strata tend to use these colors in addition to other ones.

The cards' size often varies depending relatively on the socioeconomic status of the wed-couples as they cost more money (the larger the invitation cards, the higher the socio-economic rank), but may also reflect the attitude of the card writers or the hosts' personal touch. Similarly, Momani and Al-Refaei (2010) report that the card size relies on either the inviter's taste or the financial situation. The size is an optional feature of Iraqi WICs.

In the present corpus, the use of images and pictures like doves, roses, wedding rings, fictitious portraits of bride and groom, hearts, bells, bouquets of mixed flowers, and persons plays a significant role in communicating a lot of the meaning-making of this genre. Though not frequent, the unique use of persons' images stands out in Iraqi WICs wherein the groom's and/or the groom's father's image are printed. The same tendency does not apply to the bride and the bride's 
family. This can entail a cultural implication of gender inequality and unequal distribution of power in relationships. Such use of images is often noted with families coming from rural areas and villages. Other images and symbols are neutralized in terms of region, socioeconomic status, education, etc. This means that these symbols appear across the entire corpus. It has been observed that only Iraqi WICs employ persons' images as a component portion of this homely genre compared to different regional and international contexts (Clynes and Henry 2004; Al-Ali 2006; Faramarzi et al. 2015). The use of people's images is important in negotiating the public domain of these printed WICs in the Iraqi context.

Iraqi WICs are often printed in special types of paper ranging from low to high quality. Sometimes other materials like plastic or wood are mainly used by families coming from higher socio-economic class. In the present corpus, it has been noted that the card materiality and print quality is largely affected by the socio-economic status of the future wed-couples. In general, the materiality options of cards and prints can carry an ideological implication that weddings have an elevated status in Iraqi society as in other world contexts (Fei 2004).

Also, Iraqi WICs are often printed with the beautiful art of Arabic calligraphy. The different component moves of WICs are printed in fancy decorative fonts with varying sizes and types to draw the guests' attention. The choice of the font size and type varies significantly according to the celebrating families' interests. Another nonlinguistic feature that attracts attention in Iraqi WICs is the use of diversified embellishments such as fanciful ribbons, colored beads, flowers of different types and sizes, and the like. Different ink colors are used in the cards print such as blue, black, golden, etc., and different sorts of envelopes are carefully selected to go with the invitation design.

\subsection{Linguistic features of wedding invitations}

The analysis of the present corpus at hand revealed that the schematic structure of Iraqi WICs is built around seven component moves that generally come in the following sequential order, and some of them 
are optional. Table 1 presents the identified rhetorical moves of Iraqi WICs.

Table 1. Distribution of the generic component moves of Iraqi WICs

\begin{tabular}{l|l|c}
\hline \multicolumn{1}{c|}{ Component moves } & \multicolumn{1}{|c}{ Communicative functions } & No. \& \% \\
\hline M1. Opening & $\begin{array}{l}\text { Initiating the wedding invitations by using } \\
\text { Quranic verses, Prophetic prayers and literary } \\
\text { quotations }\end{array}$ & $\begin{array}{c}250 \\
100 \%\end{array}$ \\
\hline $\begin{array}{l}\text { M2. Inviting the } \\
\text { guests }\end{array}$ & $\begin{array}{l}\text { A conventionalized expression or phrase } \\
\text { requesting the honor of the guests presence } \\
\text { and participation }\end{array}$ & $\begin{array}{c}250 \\
100 \%\end{array}$ \\
\hline $\begin{array}{l}\text { M3. Identifying the } \\
\text { hosting families }\end{array}$ & $\begin{array}{l}\text { Naming the celebrating guardians who have } \\
\text { issued the wedding invitations }\end{array}$ & 250 \\
\hline $\begin{array}{l}\text { M4. Identifying the } \\
\text { wed couples }\end{array}$ & Naming the future wed couples & $100 \%$ \\
\hline $\begin{array}{l}\text { M5. Identifying the } \\
\text { marriage } \\
\text { arrangements }\end{array}$ & $\begin{array}{l}\text { Details about the time and place of wedding } \\
\text { occasion }\end{array}$ & $\begin{array}{c}250 \\
100 \%\end{array}$ \\
\hline M6. Closing & $\begin{array}{l}\text { A conventionalized expression or phrase } \\
\text { concluding the wedding invitation }\end{array}$ & $250 \%$ \\
\hline M7. Notification & $\begin{array}{l}\text { Further information about the wedding } \\
\text { occasion }\end{array}$ & $200 \%$ \\
\hline
\end{tabular}

The opening move is an introductory component that is obligatory and comes first in Iraqi WICs. Its distribution constitutes 100\% of the entire corpus. It appears in the central top position of the wedding cards printed in different Arabic calligraphies with a variety of font type and size. This opening element has the main communicative function of announcing the invitation. It is often realized by conventionalized and formulaic clichés cited from Quranic verses, Prophetic prayers and blessings, or extracts of Arabic verse or prose. The formulaic openings are mainly restricted in their use to wedding invitations serving the publicization of the wedding significance. AlAli (2004) and Momani and Al-Refaei (2010) report the use of some of these clichés in their research. All these clichés are functional in 
enhancing the marriage promotion. The general tendency in Iraqi WICs is the use of one of these opening quotations, but sometimes, two opening types are used as well such as Quranic verses along with prayers. The frequent use of Quranic verses in the corpus analyzed can be interpreted as

a sign of adherence to Islamic teachings resulting in achieving solidarity among the members of Muslim community. According to Islamic teachings and prescriptions, starting wedding invitations cards with God's words brings bounty and security to the wed-couples. So it is a blessing to start marriage with God's words (Momani and Al-Refaei, 2010, p. 67).

Similarly, Davidson (2015) remarks that the use of Quranic verses is meant to "bestow blessings on the bride and groom for the journey ahead of them" (p. 22). The following opening Quranic verse is frequently cited in the present corpus:

$$
\text { "ومن اياتة ان خلق لكم من انفسكم ازواجا لتسكنو ا أليها وجعل بينكم مودة ورحمة" }
$$

1. (And of His signs is that He created for you wives from among yourselves, that you may dwell in tranquility with them. And He has put love and mercy between your (hearts): verily in that are signs for those who reflect).

(Al Rum, verse 21)

The openings based on prophetic prayers and blessings take the following form in the present corpus:

$$
\text { "اللهم بارك لهما وبارك عليهما واجمع بينهما بالخير" }
$$

2. (May Allah bless them and bring His blessings upon them and bind them with harmony and goodness).

The formulaic use of such prophetic prayers and invocations "has its roots in Prophet Mohammed's sayings which asked Allah's blessing, unity, harmony and love for the newly married couple" (Al-Ali 2006: 699). Another variety of opening clichés is the use of some lines quoted from either Arabic verse or prose. The following are some literary opening examples from the present corpus:

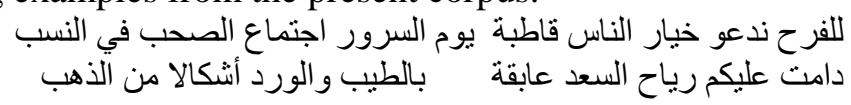


3. $(\mathrm{O}$, we request the attendance of all good fellow people, it is our heyday when we gather in our joyful wedding day. May linger your happiness wind blooming with its pleasant fragrance and golden flowers of various kinds).

The aesthetic tone of literary language, whether in verse or prose, in Iraqi WICs strengthens or makes the words used more compelling and effective on the part of guests. The literary language used adds a personalized flavor and touch to WICs resulting in making the wedding event memorable. Newly-wed couples often resort to citing from famous Arabic verse and prose to rejoice every moment of this special occasion.

The second component identified is the move of inviting the guests occurring in all the texts analyzed with a 100 percent. This obligatory component constitutes the backbone of the wedding invitation genre since the principal purpose of any wedding invitation is to request the presence of guests to attend and participate in the wedding ceremonies. With this move, the inviting guardians ask courteously and cordially the honor of guests' presence to share the joy with them. This move is typically realized by a conventionalized phrase form requesting the honor of the guests' presence and participation. Typically, the present Arabic verbal form "يتشرف" (request the honor of your presence) is the key lexical item used to tag this move. It is normally printed with a large font size in the midst of the WICs. Consider the following example from the present corpus:

$$
\text { يتشرف بدعوتكم لحضور حفل زفاف }
$$

4. (The guardians request the honor of your attendance and participation in the wedding party ...).

The third move found in the present corpus identifies who is hosting the wedding ceremony. In this component, the names of people issuing the wedding invitation are identified. It constitutes $100 \%$ of the entire corpus establishing its obligatory status. Invitations are generally issued by the bride and groom's fathers without necessarily referring to the mothers of either, or in some cases, the groom's father only. The name of the groom's father is printed first on the right-hand side before that of bride's father in the entire corpus. 
This prevailing tendency has a sort of socio-religious basis. It can show the paternal dominance and authority. In addition, it stresses the crucial role of male guardians in wedding ceremonies stemming from Islamic laws saying that "There can be no marriage without a guardian [wali] and two honest witnesses" (Nasir 1990: 54). Moreover, stating the name of groom's father only reflects the unequal distribution of power in this social context.

It is worth noting that in Iraqi culture, though the fathers of both the bride and groom are stated in the invitations, it is the sole responsibility of the groom's father paying for the event to issue the invitation, and not the bride's father. Accordingly, there is a minimal reference to the names of bride's father, as 20 percent of the present corpus does not include their names compared to those of groom's father constituting 100 percent of the present corpus. This accentuates the unequal distribution of power in this ceremonial context. Unlike in some Western English-speaking countries (like UK and USA) where the persons hosting the wedding event can issue the invitation and thus their names are stated (Monger 2004). Also, all Iraqi WICs are compulsorily issued by the guardians or parents of the bride and groom, a choice which is optional in the American or British WICs where this issue can be negotiated between the bride and the groom and their families (Johns 1997). Thus, one can find it is the bride and groom who issue their wedding invitations without referring to their families in an English context. Again this cultural preference highlights the collectivistic nature of Iraqi society where familial interdependence and authority are emphasized in comparison with the individualistic nature of most English-speaking countries where autonomy and independence of individuals are highly sought. Names along with titles are normally printed with a large and bold font face.

This component is full of titles of different kinds. Social, professional and religious titles are annexed before the inviting hosts. Religious titles (such as Hajj and Said), professional titles (such as doctor, lawyer, engineer, etc.), and social titles (such as $M r$, Sheik, the father of someone, etc.) are frequently annexed before the hosting fathers. Iraqis like most Arabs show their unconscious concern of 
social status. Al-Omari (2008) confirms that most Arabs are "nonegalitarian where position and status can dictate a mode of conduct that varies according to the individual being addressed" (p. 35). Through titles, the inviting guardians "exhibit a sense of selfpromotion as these titles reflect their social status" (Al-Ali 2006: 701).

It has been observed in the present corpus that the inviting fathers frequently use familial and tribal titles at end of their given names. This cultural entailment finds its roots in the collectivistic nature of Iraqi society. Collectivistic societies, like the most Arabic-speaking countries, are driven more by familial and tribal submission than to individualistic identity (Hofstede 1997). The same finding has been reported in Al-Ali's (2006) and Momani and Al-Refaei's (2010) research, in which such a tribal affiliation is seen as an inherent property of the Arabian society on social occasions and events. In a few instances of the present corpus, when the father of either the bride or groom is dead, the grandfather, the eldest brother or the eldest uncle takes the initiative to issue the wedding invitation. This highlights that Iraqis are a kinship-based society where interdependence and support among nuclear and extended family members are preserved, and old people are greatly revered and age is highly appreciated.

As to the fourth move of identifying the wed couples, it occurs in all the invitation texts analyzed with a 100 percent. This component typically identifies the groom and bride's names, usually their first given names. Their names are printed with a large font size but not larger than the names of their guardians reflecting the ideology of paternal authority and dominance. The corpus analysis reveals that the name of groom is typically printed before that of the bride on the same line. This preference can have its origin in the socio-religious standing of Iraqi society. According to Muslims' belief, men are protectors and maintainers of women because Allah has given men more strength than women, and men support them from their means. That is to say "a man is thought to be the guardian of a woman and remains the instrument of social control after she marries" (Al-Ali 2006: 702). Also, it can show the men's power status in the Iraqi society. Contrary to other cultures, in British or American context, for instance, the 
name of bride typically comes before that of the groom (Tol 2005: 165).

Though it is customarily expected to find the names of both bride and groom, there is minimal use of the bride's name, unlike groom's name typically identified in the corpus analyzed. It is as if the bride's name is a taboo, thus the bride's given names are euphemized and substituted by honorific expressions such as kariimatuh (his venerated daughter), or shaqiiqatuh almassoon (his honorable sister). In $30 \%$ percent of the present corpus, no reference is made to identify the bride's name; that is, the bride's name is totally omitted whereas the groom is explicitly named. This textual attitude has been rooted in the Iraqi societal system where the names of females are preferably kept to be unstated in public, and be only used in inner social groupings. Some Iraqi conservative families prefer not to print their brides' names in the WICs. For those who are outsiders of the Iraqi society, this can be interpreted as a loss of identity for women in this future relationship. Nevertheless, there is a recent tendency to state the names of the brides in WICs, and this can be attributed to women's more awareness of their equal civil rights.

As with the third move, this move is noted for the frequent use of social and professional titles annexed before the names of grooms and brides, such as Miss, doctor, engineer, professor, etc. The use of certain professional titles generally indicates the socio-educational status of the newly-wed couples emphasizing, in turn, the hierarchical organization of the Iraqi society. In fact, titles such as doctor or engineer are highly prestigious and respected among Iraqi families. Explicit reference to such professional titles can be interpreted as a sense of self-promotion since these titles reflect social status (Al-Ali 2006).

The fifth move of identifying the marriage arrangements identifies where and when the wedding ceremonies will be held. It makes explicit reference to the date and location variants of the wedding arrangements to help the invited people attend the occasion. It is an integral part of the wedding invitations as it constitutes $100 \%$ of the present corpus assuming its obligatory status. 
As to place variant, the corpus analysis reveals that Iraqi wedding ceremonies are held in the residence of the groom's parents $(65 \%)$, wedding halls $(30 \%)$, or hotels' reception halls $(5 \%)$. The dominance of holding wedding ceremonies in the groom's parental domicile can be interpreted as a sign of either the socio-economic position or the conservative standing of the groom's family. Some Iraqi families are relatively concerned about celebrating their weddings in big festival halls or hotels' halls stemming from their religious or regional backgrounds. Other place variants are relatively preferred by uppermiddle and high rank families. With this place variant, guests are often provided with a full address including the neighborhood's name, the street's name and/or any other specific landmarks.

The 'time' variant specifies the exact date and timing of wedding celebrations. It has been noted that Thursday and Friday are often selected for the wedding ceremonies in the present corpus. Thursdays and Fridays are encoded with religious connotations. These two days are considered to be blessed days for most Muslims due to the fact that Friday is a holiday for all Muslims where they assemble together to share their common public prayers. Al-Ali (2006) confirms that Friday is "a traditional day to get married, according to Islamic tradition" (p. 703). According to Prophetic Traditions, Thursdays are blessed days wherein Allah has created Heaven. Besides, Iraqi people generally have fewer working hours on Thursdays; so its evening is the best time to have fun and party all night long and to take rest the next off day. In the time variant, days are more specified by adding months and years plus the exact timing of the wedding ceremonies. The following example is extracted from the present corpus:

$$
\begin{aligned}
& \text { وذلك يوم الخميس المو افق 8-1- } 2015 \text { الساعة الرابعة عصر ا في داره الو اقعة في حي }
\end{aligned}
$$

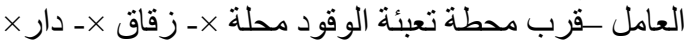

5. (This will take place on Thursday 8-1-2015 at four pm at the groom's permanent residence in Hayalaamil Neighborhood near the Gas Station, Avenue No. $x$, Section No. x, House No. x). 
The sixth move is that of closing which occurs in all the texts analyzed with a 100 percent. The WICS are generally closed off by a set of conventionalized culturally-based expressions taking the plea form by means of which the hosts heartedly appeal to their guests' attendance and their participation that makes the celebration more glamorous and pleasant. The following closings are the most frequent ones in the present corpus:

$$
\text { وبحضوركم يزدان الفرح رونقا وبهاءا }
$$

6. (Your attendance will embellish our celebration with glamor and splendor).

7. (Your attendance will accomplish our joy and happiness)

Notification is the last component move as it constitutes 8 percent of the present corpus. Some supplementary information is optionally provided and printed in small font size on either the left or right hand side of the invitation cards. It includes information or notes which should be observed by the guests. These notifications can take the form of overt appeals for not bringing children or cameras to the wedding celebration, and delimiting the number of attendants to the party. The following are some examples from the present corpus:

8. (Please, do not bring children)

$$
\text { الرجاء عدم اصطحاب الاطفال }
$$

$$
\text { ادارة النادي تمنع اصطحاب الاطفال والتصوير خلال الحفل }
$$

9. (The wedding hall's staff do not permit accompanying children and taking pictures)

$$
\text { عدد الحضور ثناثة اشخاص فقط }
$$

10. (The number of attendants should not exceed three persons)

These notes serve the organization of the wedding reception. The notes of not bringing cameras and delimiting the number of people attending are loaded with cultural implications in that some Iraqi conservative families do not show tolerance towards taking photos for their female daughters, sisters, and wives on such occasions in order not to be publicized for unknown male people. This partly stems from 
the traditional Islamic prescriptions and Arab conventions. Such a conservative view is closely related to the maintenance of family honor which is one of the highest values in the Arab society. In this respect, Nydell (2006) maintains that "women interact freely only with other women and close male relatives. Guarding a woman's image is neither a personal nor a family choice; it is imposed by the Arab culture" (p. 45). Also, this cultural practice is derived from the Quranic verse saying:

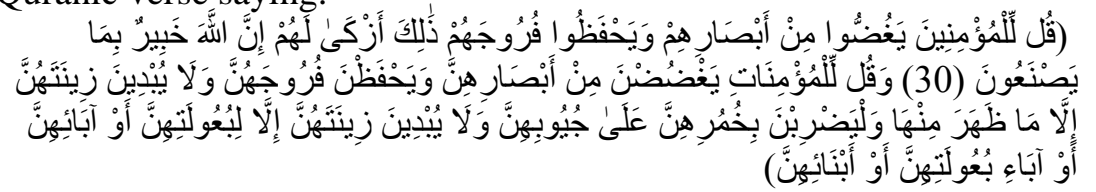

11. (Say to the believing men that they should lower their gaze and guard their modesty.... And say to the believing women that they should lower their gaze and guard their modesty; that they should not display their beauty and ornaments except what must appear thereof; that they should draw their veils over their bosoms and not display their beauty except to their husbands, their fathers...(it goes on to list male relatives, small children, etc.)

(Al-Noor, verses 30-31)

The other note of delimiting the number of attendants to the wedding celebrations can possibly act as a cultural sign of the large size of the Iraqi family. Though family structure may vary from one family to another, families in the Arab world are generally large in number, and the number of family members may reach ten or more sometimes (Al-Omari, 2008). Most Iraqi families tend to be of a lot of individual members including sons, daughters, siblings and grandmothers and grandfathers, and since wedding celebrations can only hold for limited attendants, thus, hosts sometimes attempt to restrict the number of people attended.

Also, it has been observed that some detailed information regarding directions to the wedding ceremony is given through printing small maps on the back of WICs showing the directions to the wedding halls or houses. 
4.3. Socio-cultural features of wedding invitations

After examining the linguistic and non-linguistic features of Iraqi WICs, it is now the time for scrutinizing the socio-cultural aspects which are well-knitted within the discourse of these wedding texts. The Islamic religious beliefs and Iraqi socio-cultural system were clearly depicted in these texts affecting their organization structure.

So far, it has been evident that genre analysis is capable of identifying the building components of the discourse of WICs as a communicative practice. CDA, on the other hand, does not only "mirror and reflect what goes on in society, it also attempts to interpret relationships between participants and explain how [social] variables are enacted and legitimized by a particular dominant entity" (Al-Ali 2006: 705). It investigates how sociocultural elements are encoded in the wedding event, and which elements are more influential within the genre of WICs. This asserts that ideologies are typically expressed and reproduced in and through the language. Likewise, van Dijk (1998) remarks that "if we want to know what ideologies actually look like, how they work, and how they are created, changed and reproduced, we need to look closely at their discursive manifestations" (p.6).

Generally, the most influential elements affecting the discursive organization of Iraqi wedding invitation texts are Islamic ideology and familial affiliation. Thus, religious affiliation and socio-cultural system of the Iraqi society exercise control over the visual and textual organization and patterning of WICs. Islamic ideology is greatly profiled in Iraqi WICs as religion affects significantly every aspect of Iraqi social life. Al-Omari (2008) confirms that "Islam is often referred to as a way of life due to the fact that it tackles every aspect of everyday life from worship to honesty, from hygiene to hypocrisy, from money to contracts ..." (p.150). Thus, religious affiliation or belonging is essential for every person living in any Arab society in general and Iraqi society in particular. An important aspect of the social life of every Muslim is the marriage issue. Though not mandatory, marriage is highly recommended in Islamic teachings and 
prescriptions to successfully accomplish one's religion. This is very clearly illustrated in the following Prophetic saying:

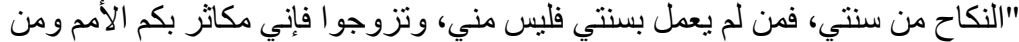

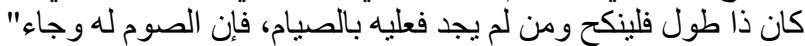

12. (Marriage is part of my Sunnah, and whoever does not follow my Sunnah has nothing to do with me. Get married, for I will boast of your great numbers before the nations. Whoever has the means, let him get married, and whoever does not, then he should fast for it will diminish the desire).

(Sunan Ibn Maja, the Chapters on Marriage)

As for the present corpus, the language of Iraqi WICs is constrained to a certain extent by the Islamic flavor. Religious touches are evidently realized in the opening move wherein Quranic verses and Prophetic invocations and prayers have frequently initiated Iraqi WICs. Such an opening seems to reflect the supremacy and dominance of Islamic religion over Iraqi social life as religion has occupied the first position in the majority of the wedding texts analyzed. The frequent use of certain religious titles introducing the hosting families such as Hajj and Said in the third component of the present corpus was noticed. These titles indicate the religious standing or status of the hosts, and can be considered as "prestigious and important titles that all Muslims long to have. It is given to a person who has performed pilgrimage or a higher religious ranking, and it connotes commitment, reverence, wisdom, and integrity" (Momani and Al-Refaei 2010: 76). And, the frequent use of executing wedding ceremonies on Thursdays and Fridays in the sixth component can be interpreted as connoting religious associations as these two days are greatly blessed in Islam.

As to the gender parameter, it is widely circulated that women in the Middle East are underrepresented and discriminated with regard to their freedom and rights. Though some of these practices are in part derived from religious beliefs, many others are cultural in nature. In most Arabic-speaking countries, and Iraq is but one, men are more involved than women in different life activities such as social, political, economic, etc. The examined corpus revealed the patriarchal 
standing and dominance of the Iraqi society. This was evident in the third and fourth component moves of identifying the hosting families and of wed-couples respectively. In these components, relatively minimal reference, and sometimes no reference, was made at all to the bride and groom's mothers' names and the bride's given name. Very few instances of the bride and groom's mothers' names were found in the present corpus, noting that not their overt given names but only covert names such as /aqiilatuh/ (his wife) are used when referring to the mother of either. Also, there was variation in the use of the bride's name in WICs as very few instances were found. Instead, expressions like /kareematuhu/ (his venerated daughter) were commonly used. However, the word /kareematuhu/ is still widely used in the Iraqi society reflecting respect for women; it can be an indication of how the general attitudes towards women's standing look like in Iraq. More surprisingly, the omission of bride's name and her parents' names was proportionally found in Iraqi WICs. References to the bride and groom's mother as such, the brides as their daughter, and the omission of the bride's name while naming the grooms can portrait the view of women in Iraqi society stressing the loss of identity for women in this social practice (Devitt et al. 2004).

According to Al-Ali (2006), the omission of the female names in Arabic WICs is due to either religious or personal preferences on the part of the groom and bride's families. This tendency can be noticed among rural and conservative urban families. In the Iraqi context, there is a general practice of not calling a woman by her first name in public and in front of strangers. Women are preferred to be called by the name of either her eldest son (the mother of someone) or her husband (the wife of someone). This might lead to the conclusion that Iraqi women are not autonomous and independent entities having an independent authority; but they are identified and designated in reference to masculine individuals, though this convention is not part of the Islamic heritage.

Embedded in the textual patternings of the wedding invitation genre is the unequal distribution of masculine power and dominance compared to that of feminine. This was clearly realized through the 
precedence of groom's name over that of bride in the entire corpus. More precisely, the groom's name is typically printed before the bride's name. Also, the groom's parents' names are typically printed before the bride's parents' names. This artifact can reinforce gender bias and unequal distribution of power in this future relationship. Other instances of gender bias and inequality in the analyzed corpus were those wherein only male guardians are in a position of issuing the wedding invitations but not female guardians. Moreover, the use of the groom's image and/or the groom's father's, but not the bride's image and her family, printed on the back of WICs implicates a cultural assumption of gender and power discrimination. One can detect that WICs are loaded with the cultural assumptions that Iraqi society is not a matriarchal-based system, and women generally look like objects or properties to be handed over from male guardians to male spouses. In the same vein, Nydell (2006) propounds that "Middle East gender roles have traditionally been governed by a patriarchal kinship system that had already existed in the regions to which Islam spread" (p.52).

In the third component move, the age axis was clearly interwoven within the discoursal organization of Iraqi WICs. The analyzed texts showed that elderly guardians, in case of deceased fathers, like elder brothers or elder fatherly uncles, have a higher authoritative standing in issuing the wedding invitation cards. In the Iraqi society, old people are highly revered and age is highly appreciated.

Closely connected to the socio-cultural aspects of the Iraqi society are paternal dominance and authority. Paternal masculine authority over the newly wed-couples was widely found in the entire corpus when issuing the wedding invitations where no wedding invitation can be issued without a male guardian like fathers, elderly brothers and uncles. Moreover, the tribe and family names were significantly attached to the given names of the inviting families and the newly wed-couples reflecting the tribal or familial affiliation and belonging. This highlights the structural organization of Iraqi family in the textual patterning of this social ceremony. This attitude is a cultural clue for the interdependence of an individual on his/her nuclear and extended 
family. It confirms the key characteristic of the collectivistic nature of Iraqi Arabic culture and society. To support this argument, Momani and Al-Refaei (2010) assert the importance of the nuclear and extended family in the person's life. In most Arabic-speaking countries, not only the nuclear family, the extended family is also a very basic cultural unit supplemented by the tribal system (p.77).

Iraqi WICs were found to be restricted by the social status variable. This cultural attitude was manifested in the excessive use of different kinds of religious, social, and professional titles annexed before the names of celebrating families and newly-wed couples. Not only textual features were found to be constrained by this variable, visual features were as well. Factors such as educational background and socio-economic were found to exercise an influential role in the visual organization of the present corpus. Certain designs, colors, sizes, and materiality of WICs were found to be restricted by socio-cultural constraints. The Iraqi Arab society, like most Arab societies, is best described as a vertically organized system where social status is highly appreciated. Social status is derived from the person's origin, professional standing, education level, or income. With the same argument, Nydell (2006) maintains that social class and family background are the major determining factors of personal status that is deeply rooted and highly influential in the societal structure of most Arab countries.

Until now, parameters of Islamic religious affiliation, paternal masculine power and gender inequality were inspected by resorting to the linguistic (lexico-grammatical features) and non-linguistic resources of the corpus analyzed. The discourse organization and arrangements can also be adopted to explore these socio-religious effects. A closer vertical look at the textual arrangements of Iraqi WICs (see Figure 1 below), one can see that most WICs are generally opened with either Quranic verses or Prophetic sayings. Religion takes the first component position dominating all other below components. The third component is normally occupied by the groom and bride's families' names divided horizontally into two sub-components starting first with the groom's father's name followed by his mother's name (if 
mentioned) then the bride's father's name followed by her mother's name (if mentioned) comes. Then the fourth component is occupied by the names of the newly-wed couples divided horizontally into two sub-components starting with groom's name first then the bride's name (if mentioned) follows.

The hierarchical textual organization of the first, third and fourth components of the present corpus can be socio-culturally read as since religion occupies the highest significant position in Iraqi society, it takes the first component position in Iraqi WICs dominating the familial system, generally considered as the second important building block of Iraqi society after religion. More specifically, dominated by religion, the family paternal authority comes second that in turn dominates that of the young wed couples on the next component. As for gender and age, they are unequally distributed in the present corpus as elderly males like fathers, elderly brothers or elderly uncles have a higher form of authority or dominance than that of females (mothers) as males' names come before females'. Likewise, the groom's names appear before the bride's. At the same time, the groom and bride's names are printed below their parents' names (Al-Ali 2006). Figure 1 summarizes the overall textual organization of Iraqi WICs with illustrative examples from the present corpus.

Move 1: Opening
In the Name of Allah, Most Gracious, Most Merciful
(And of His signs is that He created for you wives from among yourselves that you
may dwell in tranquility with them. And He has put love and mercy between your
(hearts): verily in that are signs for those who reflect).
(Al Rum, verse 21)
Move 2: Inviting the guests
Request the honor of your attendance to the wedding ceremonies of
Move 3: Identifying the hosting families
(Name of groom's father) (Name of bride's father)
Move 4: Identifying the wed couples
His son $\quad$ His honorable daughter
(Name of bride )
(Name of groom)




Move 5: Identifying the marriage arrangements
Time and address of the wedding ceremonies
Move 6: Closing
Your attendance will embellish our celebration with glamor and splendor
M7.Notification
The wedding hall's staff do not permit accompanying children and taking pictures

Figure 1. The schematic textual organization of Iraqi wedding invitation cards

5. Conclusions and implications

The present study examined how the genre of Iraqi WICs is organized and constructed to accomplish the communicative function of the wedding ceremony as a social event. More precisely, it examined how Iraqi sociocultural practices and religious beliefs are embedded in the textual and visual organization of the discourse of wedding invitations, and to understand how and why these texts were articulated in such a ritualistic artifact. The mediation between textual and visual organization of Iraqi WICs is constrained by the assumptions and beliefs of the discourse community which produces it.

The developed multi-analytic framework was able to describe the linguistic and nonlinguistic components. The nonlinguistic components included the printed form, size, layout, graphics, color, design, and paper of the cards. The linguistic components, on the other hand, involved the wording of the WICs which provided the guests with information about what to expect at the ceremony. The genre of WICs was greatly loaded with the sociocultural and religious assumptions and conventions of Iraqi society, which had, in turn, a fundamental effect on the organizational details of this communicative event or practice. That is, Islamic ideology and sociocultural assumptions such as patriarchal dominance, paternal authority, socioeconomic standing, and age were deeply depicted in the visual verbal organization of wedding invitation texts. The analysis of WICs showed the unequal distribution of power in this future relationship in 
that the dominance of the patriarchal authority was very evident, and marriage seemed to be patriarchal rituals through which the masculine power over the bride is transferred from the father before the marriage to her future husband after the marriage (cf. Al-Ali 2006). This might portrait the Iraqi marriage as a ritual wherein the bride is treated as an object exchanged between the bride's father and the bride's future husband.

The research on such homely genres, like wedding invitation cards, for instance, can highlight the common widespread socialization process from which one can learn "the rules and practices of social groups" (Worsley 1970: 27). Such research is believed to be significant for those who are interested in becoming familiar with the social behavior of members from different linguistic and cultural backgrounds. Moreover, such studies of speech behavior patterns in a variety of languages and cultures would provide interesting contributions to cross-cultural communication.

Acknowledgement

This research is supported by a grant from the American Academic Research Institute in Iraq (TAARII) for which the author is indebted. The author gratefully acknowledges the assistance and support of TAARII for Iraqi scholars and researchers.

\section{References}

Al-Ali, N. (2006). Religious affiliations and masculine power in Jordanian wedding genre. Discourse \& Society, 17(6), 691-714.

Al-Omari, J. (2008). Understanding the Arab Culture. $2^{\text {nd }}$ edition. Oxford: How to Books Ltd.

Allison, D. \& Ruiying, Y. (2004). Research articles in applied linguistics: Structures from a functional perspective. English for Specific Purposes, 23(2), 264-279.

Bhatia, V. K. (2010). Interdiscursivity in professional communication. Discourse and Communication, 21(1), 32-50.

Bhatia, K. (2004). Worlds of Written Discourse: A Genre-based View. New York: Continuum.

Clynes A. \& Henry A. (2004). Introducing genre analysis using Brunei Malay wedding invitations. Language Awareness, 13(4), 225-242. 
Davidson, N. (2015, June 19). Muslim wedding cards. [Online] Available:http://www.articlesbase.com/gifts-articles/muslim-wedding-cards4789432.html.

Devitt, A., Reiff, M. \& Bawarshi, A. (2004). Scenes of Writing: Strategies for Composing with Genres. New York: Longman.

Fairclough, N. (2010). Critical Discourse Analysis: The Critical Study of Language. London: Pearson Education Limited.

Faramarzi, S., Elekaei, A. \& Tabrizi, H. (2015). Genre-based discourse analysis of wedding invitation cards in Iran. Journal of Language Teaching and Research, 6(3), 662-668.

Fei, V. (2004). Developing an integrative multi-semiotic model. In: O'Halloran, K. (Ed.), Multimodal Discourse Analysis (pp. 220-246). London: Continuum.

Hill, O. (2015, August 15). Muslim wedding invitation. [Online] Available:http://www.articlesbase.com/weddings-articles/muslim-weddinginvitation-5386378.html.

Hofstede, G. (1997). Cultures and Organizations: Software of the Mind. New York: McGraw-Hill Companies, Inc.

Holmes R. (1997). Genre analysis and the social sciences: An investigation of the structure of research article discussion sections in three disciplines. English for Specific Purposes, 16(4), 321-337.

Johns, A. (1997). Text, Role, and Context: Developing Academic Literacies. Cambridge: Cambridge University Press.

Kress, G. \& van Leeuwen, T. (1996). Reading Images: The Grammar of Visual Design. New York: Routledge.

Kress, G., \& van Leeuwen, T. (2001). Reading Images: The Grammar of Visual Design ( $2^{\text {nd }}$ Ed.). New York: Routledge.

Leeds-Hurwitz, W. (2002). Wedding as Text: Communicating Cultural Identities through Rituals. Mahwah, N.J.: Lawrence Erlbaum Associates Publishers.

Miller, C. (1984). Genre as social action. Quarterly Journal of Speech, 70(1), 151-67.

Mirzaei, A. \& Eslami, Z. (2013). Exploring the variability dynamics of wedding invitation discourse in Iran. Journal of Pragmatics, 55(1), 103-118

Momani, R. \& Al-Refaei, F. (2010). A socio-textual analysis of written wedding invitations in Jordanian society. LSP Journal, 1(1), 61-80.

Monger, G. (2004). Marriage Customs of the World: From Henna to Honeymoons. Santa Barbara, Ca.: ABC-CLIO, Inc.

Nasir, J. (1990). The Islamic Law of Personal Status. London: Graham \& Trotman Ltd.

Nydell, M. (2006). Understanding Arabs: A Guide for Modern Times (4 ${ }^{\text {th }}$ ed.). Boston: Intercultural Press, Inc. 
Wedding Invitation Genre: Communicating Sociocultural Identities 155

O’Halloran, K. (Ed.). (2004). Multimodal Discourse Analysis. London: Continuum. Sadri, E. (2014). Iranian wedding invitations in the shifting sands of time. RALs, 5(1), 91-108.

Sharif, M., \& Yarmohammadi, L. (2013). On the Persian wedding invitation genre. SAGE, 3(3), 1-9.

Swales, J. (1990). Genre Analysis: English in Academic and Research Setting. Cambridge: Cambridge University Press.

Tol, A. (2005). The Bride's Handbook: A Spiritual and Practical Guide for Planning Your Wedding. Miami: Fleming H. Revell Publishing.

Van Dijk, T. (1998). Ideology: A Multidisciplinary Approach. London: Sage.

Worsley, P. (1970). Introducing Sociology. Harmondsworth: Penguin. 